\title{
The Multiple Casualty Scenario: Role of the Anesthesiologist
}

\author{
Christopher M. Lam ${ }^{1} \cdot$ Michael James Murray ${ }^{2}$ \\ Published online: 29 June 2020 \\ (C) Springer Science+Business Media, LLC, part of Springer Nature 2020
}

\begin{abstract}
Purpose of Review Mass casualty disasters (natural and man-made) present an acute, critical situation that taxes healthcare resources and clinician acumen. This review summarizes the characteristics and management skill sets that anesthesiologists possess that make them valuable clinicians during mass casualty events and why we as anesthesiologists must continually educate ourselves on this important topic.

Recent Findings Anesthesiologists should be involved in all aspects of emergency preparedness - mitigation, planning, response, and recovery. The anesthesia department should have a plan for how it will deal with managing patients during natural and man-made (unintentional or intentional) disasters, one that takes into account a risk hazard analysis and institutional goals. Unfortunately, most practicing anesthesiologists have not had training and ongoing education for such events, and few academic centers train anesthesiology residents and staff to prepare for mass casualty scenarios.

Summary The everyday clinical practice of anesthesiologists involves the utilization of some of the skills (vascular access, tracheal intubation) commonly required to successfully manage mass casualty scenarios. Anesthesiologists' knowledge of anti-cholinesterases makes them subject matter experts on nerve agent poisoning, and their experience managing trauma patients will serve them well, depending on the nature of the mass casualty event. Practicing anesthesiologists however need to continually educate themselves on their role during mass casualty events. and current anesthesiology residency programs should develop a curriculum and incorporate simulation training to better prepare future generations of anesthesiologists.
\end{abstract}

Keywords Anesthesiologist in austere environments · Anesthesiologists and mass casualty scenarios $\cdot$ Anesthesiologists and nerve agents - Anesthesiologists and major disasters - Anesthesiologists and resuscitation - Anesthesiologists and emergency preparedness

\section{Introduction}

Leaders in anesthesia have advocated for the involvement of anesthesiologists in disaster preparedness for decades [1-5]. Practicing anesthesiologists however may not regard the topic as relevant to their everyday practice for

$\overline{\text { Christopher Lam and Michael Murray are the authors who contributed to }}$ the literature review and writing of this manuscript.

This article is part of the Topical Collection on Anesthesia for Trauma

Michael James Murray

Michael.Murray@bannerhealth.com

1 Department of Anesthesiology, University of Kansas Medical Center, Kansas City, KS, USA

2 Departments of Internal Medicine and Anesthesiology, Banner University Medical Center-Phoenix, 1111 E McDowell Rd, Phoenix, AZ 85006, USA the same reasons that other physicians do not: (1) a mass casualty event will not happen here, (2) anesthesiologists with military experience should be involved, and (3) governmental resources will be available. These views are not realistic firstly because the incidence of natural (Fig. 1) [6] and man-made disasters (Fig. 2) [7, 8•] continue to increase $[9,10,11 \bullet \cdot]$. Secondly, the kinds of injuries caused by intentional man-made disasters, once seen only during combat, are now being seen in civilian hospitals [12] and require a change in our educational paradigms [13] and for practicing anesthesiologists, a need for preparedness. Thirdly, it may take hours, as many as 24 or more for the government to mobilize and respond. Finally, as we found during the COVID-19 pandemic, which some have seen as a "medical disaster" [14], that should be managed as any other mass casualty event, anesthesiologists, especially anesthesiologists with critical care training, are the most sought after members of the health care team $[15,16]$. As members of the communities in which we practice we have 
Fig. 1 Annual incidence of natural disasters in the USA over the past five decades

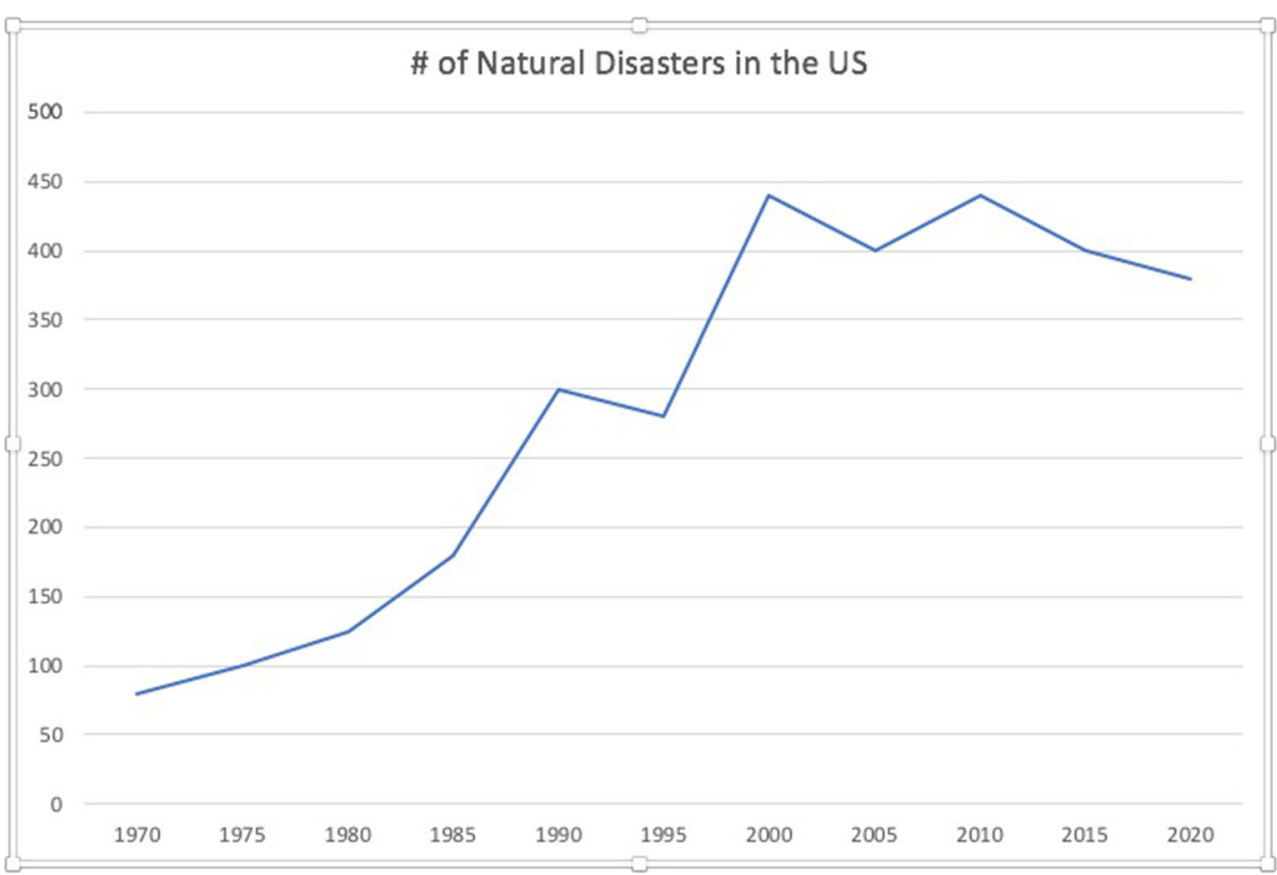

a civic duty to help our neighbors should calamity strike, and the best way to do that is to plan and be prepared.

\section{Definitions}

The World Health Organization defines a disaster as "A serious disruption of the functioning of a community or a society causing widespread human, material, economic or environmental losses which exceed the ability of the affected community or society to cope using its own resources" [17]. A mass casualty incident refers to a situation in which a number of "casualties" arrive at a hospital, and though the number of patients may challenge the capabilities of the facility and staff, the hospital has the resources to manage the influx, whereas a mass casualty event arises when the number of patients overwhelms the facility's resources, often times necessitating a request to state or federal agencies for assistance. A large urban hospital with a Level 1 Trauma Center is in a much better position to handle 10 trauma patients (incident) than a small rural hospital (event). However, a large urban hospital may be overwhelmed if the facility loses electricity due to a hydrometeorological event or sustains structural damage from a geological event.

\section{Background}

Whether man-made or natural (e.g., Ebola and SARS epidemics and the SARS-CoV-2 pandemic are "natural" but to some extent "man-made" events, in the sense that they are caused by ingestion of meats that are not acquired nor prepared in ways that minimize the transmission of infectious agents), mass casualty situations often result in critically ill patients that require resuscitation. The resuscitation can vary therefore, based on the etiology of the injuries or disease. Specific to geophysical disasters a classification system has been proposed by various organizations to maximize efforts to provide care to those that have higher likelihood of surviving their injuries. A report by the Disaster Reanimatology Study Group that gathered information on earthquake survivors from Armenia (1988), Costa Rica (1991), and Turkey (1992) as well as the autopsy reports after the Great Hanshin-Awaji earthquake in Japan (1995) [10] demonstrated several notable characteristics of the mortality profile of patients.

Most deaths were similar to what is seen in combat, nonsurvivable injuries to the head, chest, or abdomen. One third of all deaths occurred within hours to days and could be categorized into two groups. One group consisted of minimally injured patients who were unable to receive appropriate care in a timely fashion (e.g., because extrication from collapsed buildings was prolonged), and even though the injuries were relatively minor, the delay in receiving care led to organ injury that then resulted in death within $24-48 \mathrm{~h}$. The second group of patients consisted of severely injured patients that were found in a timely manner but had delay in transport to receive appropriate care. From these findings a 4-class system was created to group patients to help identify those with the highest likelihood of rescue, of which class 3 (patients with intermediate injuries who can be stabilized with simple measures such as fracture stabilization or maintaining airway until further help arises) had the greatest chance of surviving [10]. The 
Fig. 2 Incidence of man-made disasters. a Annual number of mass shootings in the USA within the past four decades. b Annual number of worldwide terrorist explosive events within the past five decades

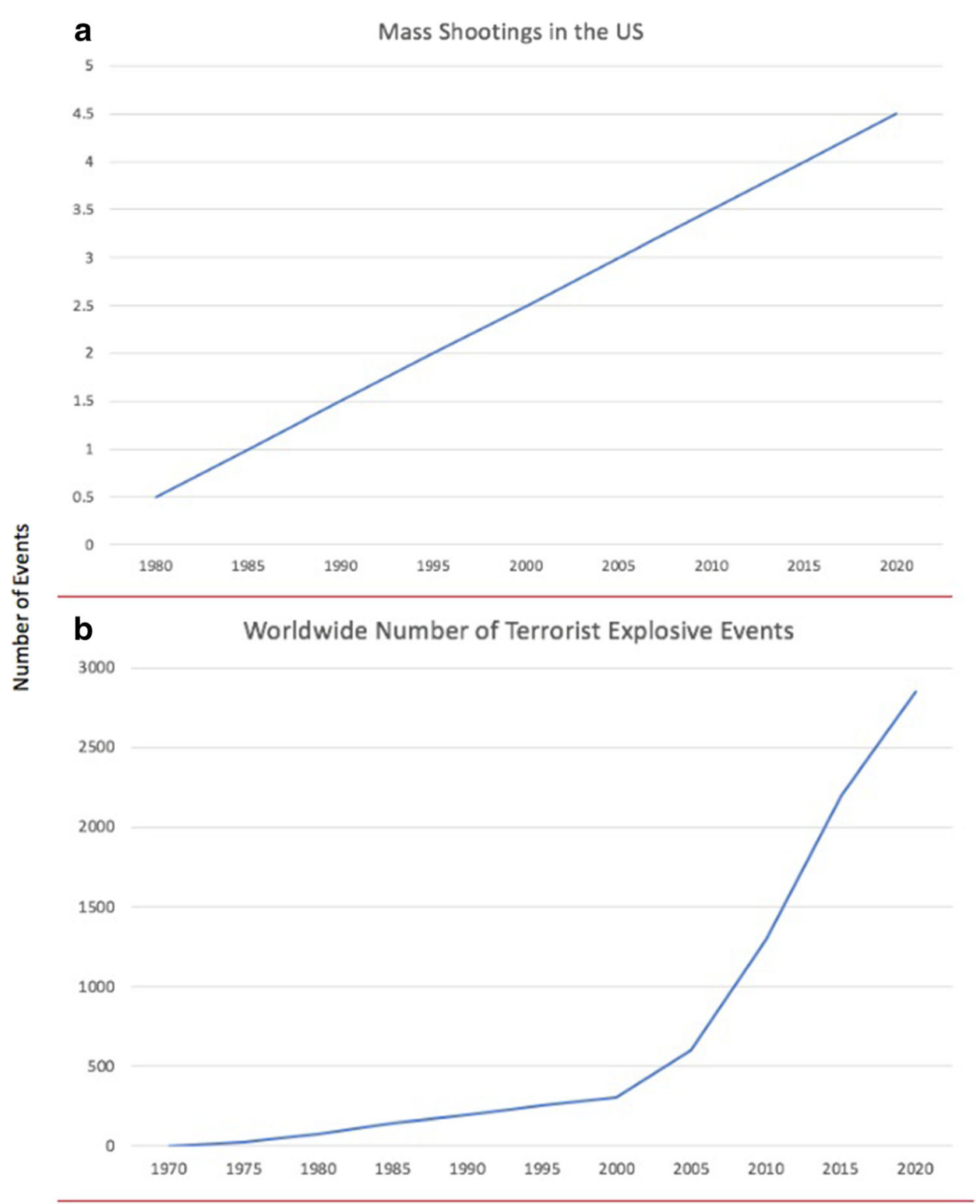

conclusions of the study were that a better system of triage at the injury site would lead to an overall improvement in survival for the greatest number of casualties. This conclusion has been made multiple times over the last several decades when dealing with mass casualties from geologic events, or from intentional man-made (terrorist) events. As important as these observations are, the reality is that many patients arrive at a hospital emergency department (ED) without any triage either at the site of injury, or at a triage site outside the ED. Independent of whether or not a patient has been triaged or not, whether a patient has been partially resuscitated or not, if an anesthesiologist is assigned to manage a patient, he or she must provide the highest level of care possible under the circumstances in which she or he is practicing.

\section{Disaster Management}

Effective disaster management is divided into 4 phases: mitigation, planning, response, and recovery.

Mitigation Anesthesiologists are unlikely to be involved in this phase, which decreases the risk of loss of life and injury by establishing for example, building codes that will mitigate the effects of hurricanes or earthquakes. However, in terms of mitigation an anesthesiologist should avoid purchasing a home in a flood plain or a house that does not meet building code; otherwise, they may not be available if and when disaster strikes. Likewise, they need to be aware that an evacuation during a hurricane or road closures following a terrorist attack 
may limit access to transportation or to roads normally used for traveling to the hospital and therefore should have planned in advance how they would travel to the hospital.

Planning Similarly, long before a disaster strikes individuals should have prepared a family emergency plan [18] and a personal response plan. In a severe storm electricity is often lost, therefore, have cash and a car refueled because automatic teller machines and gas pumps require electricity to function. Of even more importance, the hospital's anesthesia department should be prepared. Departmental leaders should have characteristics that help them to effectively respond to the disaster, i.e., knowledge of incident command and of trauma anesthesia, and good communication and problem-solving skills [19]. Unfortunately, as the recent COVID-19 pandemic demonstrated some medical departments did not realize that a command center would be of benefit until the pandemic occurred [20].

Because true mass casualty events are uncommon, it is difficult to adequately prepare, but there are several options though that can be utilized to prepare for a disaster. Regulatory agencies require that hospitals have semi-annual disaster management drills. Departments should request that such drills require the involvement of not only departmental leadership but the department staff as well. If hospital leadership is unwilling to include anesthesiologists in disaster drills, departments can use experience gained in mass casualty incidents to help prepare and train for mass casualty events [21]. Simulation training can be used in evaluating personal protection equipment (PPE) worn when managing patients with infectious biologic agents or contaminated by chemical or radiologic agents [22]. If simulation is not an option, individuals can train donning and doffing PPE in a controlled environment before ever actually caring for patients, as the Chinese did during the COVID-19 pandemic [23].

As we realized during the COVID-19 pandemic, organizational preparation from local, regional, and national disaster planning is paramount for successful response. However, comprehensive physician input has not always been sought or implemented [24]. Concern regarding adequacy of physician preparedness for mass casualty situations was poignantly noted as early as the 1950s [25]. Later in the 1970s a survey of physicians in Massachusetts revealed that most physicians have not been invited to participate in community disaster preparedness programs even though $48 \%$ said they would attend if invited [26].

Since then, the need for training in these events has been identified yet active implementation of such training programs has been slow to be adopted for residency programs. A survey was sent to program directors or chairpersons for 135 accredited US anesthesiology residency programs with response from 90 programs in 2005 showing that only 33 $(37 \%)$ of the responders had any form of training to care for patients inflicted with weapons of mass destruction [27]. Of this group, 10 of the $33(30 \%)$ had not repeated training within 2 years of the initial training. Furthermore, only 14 of the 33 programs $(42 \%)$ made the training mandatory [27].

Response The standard "minimal but acceptable care" maximizes the ratio of patients being treated to the resources available [28]. Commonly utilized healthcare resources (e.g., oxygen and blood products) are quickly depleted if not effectively managed [29, 30], a point underscored during the COVID-19 pandemic when many efforts were made to conserve oxygen [31].

During mass casualty disasters many patients do not wait for emergency medical services (EMS) transport and will quickly find and utilize the nearest hospital facility, not necessarily the one most appropriate for their care. Hospitals closest to the site of the disaster may find that staffing is a significant limiting factor to the number of patients for whom they can provide care. Multi-institutional surveys of hospitals throughout the USA have uniformly shown that the majority of hospital employees were willing to report during these disasters. Those who are unable often have conflicting emergency responsibilities such as caring for ill family members, or working with local fire, police, or military forces which concurrently require their attention [32], or they find that roads are closed as occurred following the October 2017 Las Vegas shooting.

Oftentimes, disasters test the capabilities of involved hospitals that typically do not care for certain patient populations regularly. A case example of this was during the July 14, 2016, Bastille Day Attack in Nice, France, when Lenval University Children's Hospital (LUCH) was charged with the care of several adult trauma patients [33]. In total, 47 patients were evaluated at LUCH of which 11 required surgery (including 3 adults). Of the 47 patients that were evaluated, 5 died (one adult, four pediatrics) with a mortality of $10.6 \%$. A review of the planning by the authors after the event identified several key actions for success including hospitalwide resource management including making open beds available, maintaining staff on duty, a means to notify staff at home of the event, preparing the trauma bay with resuscitative tools, and making a second area accessible for non-mass casualty incident emergencies [33].

Ensuring smooth transition to initiate care for mass casualty events requires not only clinical expertise but organizational familiarity. A survey of emergency response personnel for key attributes for effective disaster responders and leaders was published in 2016. The findings of this study showed that aside from medical knowledge and cognitive ability, interpersonal proficiencies including communication skills and decision making as well as calm demeaner ranked in the top 10 of desirable attributes of leaders during mass casualty incidences [34]. Interestingly, this survey was resent later with findings 
published in 2019 that showed that while the same attributes were deemed important, greater emphasis was placed on interpersonal skills such as communication and decision making, which were ranked more important than cognition and knowledge for leaders [35•].

Modern-day anesthesiology practice in the USA incorporates a multifaceted care team model where attending anesthesiologists work within a team-based health care environment. Aside from working with other staff anesthesiologists, fellows, residents, and nurse anesthetists, anesthesiologists coordinate patient care with perioperative nurses, technicians, perfusionists, and physicians from other services. Their clinical skillset makes them uniquely qualified to assist during mass casualty disasters.

Outside of the USA anesthesiologists have roles that expand outside of the hospital environment. During the Egyptian Revolution in 2011, anesthesiologists were used in trauma resuscitation rooms to resuscitate patients as well as triage them to the intensive care unit or medical-surgical ward prior to surgery [30]. The 2013 Rana Plaza tragedy in Bangladesh highlighted the extensive role anesthesiologists had in managing casualties [28]. During the various mass casualty situations in Israel, anesthesiologists likewise play a significant role outside the OR [36].

In Europe, notably France, anesthesiologists have a large role in prehospital care; they participate in the Service d'Aide Medicale Urgente (SAMU). The French casualty management plan is two tiered with red and white plans. The red plan is focused on managing the cause of the mass casualty while extricating and rescuing patients. Once triaged, the white plan is instituted during which evacuation from the site and resuscitation begin $[37,38]$. Aside from resuscitation, anesthesiologists provide regional anesthesia services to patients with orthopedic injuries en route to the hospital. Should a patient decompensate, transport is stopped and the anesthesiologist manages the resuscitative efforts.

The difference between the US and international philosophies for prehospital care may be due to the etiology of the traumatic event. In the USA, there are greater numbers of patients with penetrating trauma in which fluid resuscitation and medical management has a limited role as surgical intervention is the definitive treatment. In Europe, however, the majority of patients have blunt trauma in which there is more of a role perhaps for fluid resuscitation prior to transport. As a result, US disaster medicine focuses on urgent transportation to trauma centers for evaluation and definitive treatment [38].

\section{Phases of Care}

Three general phases of care exist in management of mass casualty patients including prehospital care, triage, and inhospital care $[10,37]$. Prehospital care includes the efforts of extrication, basic and advanced life support, and stabilization care prior to arrival to the hospital. Triage includes the risk stratification and placement of patients into appropriate care teams, while in-hospital care encompasses the execution of the care plan whether it be operative or medically based. In the USA, as mentioned previously, anesthesiologists focus on the perioperative care of patients in hospitals. The types of disasters for which their skill sets might play an important are many.

\section{Natural Disasters}

Compared to the rest of the world, we in the USA are relatively fortunate, but not completely so, in that the effects of the weather (hurricanes, tornadoes, drought - increasing the number of forest fires) have not been as severe as seen elsewhere in the world where over one half people are affected annually [39]. However, if you experienced first-hand hurricane Sandy, or the Northfield earthquake of 1994, or developed acute respiratory failure from COVID-19, then you know well that Mother Nature can throw quite a punch, one that the entire planet strives to avoid.

Meteorologic (Storms), Hydrologic (Floods), and Climatologic (Extreme Temperatures) In September 2017 Hurricane Irma, at the time the most powerful Atlantic storm ever, hit the Caribbean and the South-east USA, causing $\$ 77.2$ billion in damages and resulting in 134 deaths, 92 in the USA. Flooding disabled many hospitals. Those hospitals still functioning had to provide care for "routine" cases such as caesarian sections and appendectomies, those transferred from other hospitals, and those injured by the primary and secondary effects of the storm. For staff at those hospitals, the basics mentioned above were critical, i.e., family and personal plans, ability to function without electricity, means of communications, and maintenance of physical and mental health [40].

Geologic Earthquakes fortunately are not as common as weather-related disasters, but morbidity and mortality can be significantly higher. Because many hospitals are destroyed or non-functional, transportation of casualties out of the earthquake zone to healthcare facilities elsewhere is a major challenge, especially if no triage has been performed. Under these circumstances, triage is critical; many can receive first aid or delayed treatment allowing for attention to be directed towards the most critically injured. The "urgent" patients are those with crush injuries or amputations requiring immediate care. The earthquake that struck Haiti in 2010 killed 316,000 and injured another 300,000 [41]. Because the island was so devastated, anesthesiologists in the USA responded to this humanitarian 
crisis, providing critically important services in a delayed fashion [42].

Biologic Viruses such as Ebola [43] and SARS-CoV-19 [16] are highly contagious and, as we have seen with the COVID19 pandemic, can create much more havoc as would the use of anthrax by terrorists. Because of their airway management skills anesthesiologists will be at the forefront of providing care for many of these patients [44•, 45-50], and for those anesthesiologists with critical care training they will likely be involved in the management of patients who are candidates for ECMO [51].

\section{Man-Made Disasters (Intentional)}

\section{Terrorism}

Chemical An area where anesthesiologists offer unique insight due to familiarity with cholinergic and anticholinergic pharmacology is the mass casualty disaster involving chemical agents. Within the chemical classification, subclassifications exist to include mustard gas and nerve agents of which two forms exist, G series volatile (tabun, sarin, soman, GF) and non-volatile agents (VX) [52-54]. Volatile agents have a boiling point higher than water, resulting in sufficient vaporization at room temperature with quick absorption and onset of agent. Non-volatile agents have a lower vapor pressure with slow onset but also slow offset due to their lipophilicity and binding nature making removal from skin and clothing difficult [52]. Regardless of chemical agent, the first line of treatment is adequate decontamination.

Mustard gas is a lipophilic agent that targets cells with high rates of mitosis (i.e., respiratory tract, gastrointestinal tract) resulting in tissue injury. Care for these patients is largely supportive as many will require airway management because of the extent of respiratory tract injury. Antibiotic treatment may be necessary at some point due to the injury sustained by the respiratory mucosa placing patients at risk of developing respiratory infections.

Nerve agents are organophosphate compounds that reversibly or irreversibly inhibit the acetylcholine esterase enzyme resulting in parasympathetic (acetylcholine) surge. Patients develop clinical symptoms including altered mental status, muscle weakness, hypersecretion, dyspnea, and miosis [55]. The familiarity that anesthesiologists have with neostigmine in daily practice, similar to radiologists who are subject matter experts for radiological injury [56], will make them subject matter experts for treating organophosphate poisoning. Furthermore, if respiratory failure is present, definitive airway management will be needed, an area in which anesthesiologists have the most expertise.
Biological In recent years the threat posed by biological agents has increased [57]. These agents include organisms that can be spread by atmospheric dispersal, food contamination, or conventional warfare agents containing biologics [54]. Commonly associated pathogens include anthrax, botulism, plague, smallpox, tularemia, and viral hemorrhagic fever. Treatment for patients afflicted with these conditions are often supportive care including intubation and mechanical ventilation on a scale that would eclipse the COVID pandemic in the locale where it was used. While this scenario might seem farfetched, not that long ago members of the Aum Shinrikyo cult traveled to Zaire with the expressed purpose of bringing back samples of the Ebola virus with the goal of using it as a biologic weapon [58].

Major (Group A) biologic agents used as weapons of mass destruction are as follows:

- Bacillis anthracis (anthrax)

- Variola major (smallpox)

- Yersina pestis (plague)

- Clostridium botulinum (botulism)

- Francisella tularenis (tularemia)

- Viral hemorrhagic fever (Ebola, Lassa, Marburg, Argentine)

Anthrax and smallpox are the two infectious agents most likely to be used as weapons of mass destruction as small inoculums of either agent are incredibility potent - they are highly infective, very contagious, and in unprotected individuals, are associated with $50 \%$ fatality rates. If small pox is used as a weapon of mass destruction, the US and state governments have prepared to vaccinate the entire population within $48 \mathrm{~h}$ to prevent the spread of the disease.

Of potentially greater concern is the aerosolized delivery of anthrax spores to large populations. The most recent data indicate that vaccination and treatment with antibiotics are the best way to provide prophylaxis against anthrax. Unfortunately, vaccination of the entire population is difficult, and we would need to rely on the use of antibiotics to control a disease that is highly infectious with a high mortality rate.

Public health care teams in the USA are recommended to be vaccinated against small pox, and US military policy is that all personnel in combat zones must be immunized against anthrax - 6 immunizations over 18 months and annually thereafter. Ciprofloxacin is an excellent for prophylaxis, but the best prophylaxis is a combination of immunization and ciprofloxacin.

Radiologic/Nuclear When it comes to radiation injury events, incidents at nuclear power plants over the last 30 years have created the most damage, destruction, and long term health problems. Public health officials, however, are concerned that terrorists might use a "dirty" bomb, one with radioactive 
material wrapped around an improvised explosive device. The sequelae from the release of radiation in a major population center such as NYC [59] would be hugely disruptive in terms of (1) the panic, (2) the amount of radioactive waste produced, (3) lost productivity and health screening of the population, and (4) resettling many displaced from their homes.

The major challenge to the healthcare system would be screening the entire "exposed" population of individuals who will demand to be examined. Most individuals will have no exposure, and the majority who are exposed will often be externally radiated only and, depending on the amount of radiation, may require no treatment. As mentioned previously, individuals who have no symptoms within $6 \mathrm{~h}$ are unlikely to require hospitalization. Symptomatic individuals should be hospitalized with serial white blood cell (WBC) counts measured. If the WBC remains stable for $48 \mathrm{~h}$, the patient may be discharged. The US and state governments plan to distribute potassium iodide tablets to protect the thyroid of all individuals potentially exposed within $24 \mathrm{~h}$ - assuming those who are supposed to distribute the tablets will do so. Individuals who have symptoms within minutes or hours of exposure will require hospitalization and treatment of the most common sequelae of radiation sickness including bone marrow failure (infection and coagulopathy), and gastrointestinal bleeding secondary to mucosal damage and the thrombocytopenia from the bone marrow failure. Antibiotics, volume resuscitation with blood products, and treatment with granulocyte colony stimulating factor may be lifesaving.

Explosive Worldwide use of improvised explosive devices is the terrorist's favorite weapon. Patients have burns, fractures, lacerations, multiple shrapnel injuries, soft tissue trauma, and traumatic amputations. As the weapons have become more sophisticated and powerful, the extent of injuries has increased significantly.

Patients with any evidence of burns to the face or airway will require appropriate airway management. Patients should be intubated, awake if possible, as a significant number of these patients will have mild to moderate glottic edema at the time of intubation. Those patients with burns must be managed aggressively with respect to fluid resuscitation. With isolated total body surface injury, fluid resuscitation is aggressive. With polytrauma and no thirddegree burns, "damage control resuscitation/surgery" is the norm [60]. For patients with extensive third-degree burns body temperature is maintained (operating rooms maintained at $>100$ degrees Fahrenheit) and surgery is performed as soon as possible to stop the bleeding decreasing the need for blood products and the chances of developing a dilutional coagulopathy. Patients who do develop a coagulopathy may benefit from a ratio of pRBCs to fresh frozen plasma to platelets of 1:1:1 as a part of their volume resuscitation related to hemorrhagic shock [61]. The
CRASH-2 study demonstrated that tranexamic acid decreases the need for additional blood products [62].

\section{Conclusions}

Modern-day disaster planning has grown to include input from physicians in emergency medicine and trauma surgery. However, anesthesiologists have not been consistently included or utilized in these scenarios and do not know the hospital contingency plans during mass casualty events [37]. Many of the daily clinical responsibilities of anesthesiologists make them well suited to manage patients during mass casualty incidents. As intraoperative intensivists who deal with difficulty airway management, resuscitation, perioperative medicine, operative resource management, and pharmacologic implementation (notable for relevant use of cholinergic and anticholinergic medications), anesthesiologists can offer a great deal during mass casualty incidents regardless of their cause. This model is already in existence in many European countries highlighting the ease and utility of similar practices in the USA. The first step towards this paradigm change requires not only increased involvement of anesthesiologists in disaster planning but also early exposure of residents through relevant training simulations.

\section{Compliance with Ethical Standards}

Conflict of Interest Christopher M. Lam and Michael J. Murray declare they have no conflict of interest.

Human and Animal Rights and Informed Consent This article does not contain any studies with human or animal subjects performed by any of the authors.

\section{References}

Papers of particular interest, published recently, have been highlighted as:

- Of importance

•. Of major importance

1. Mc NN. Anaesthesia and analgesia in the management of mass casualties. Can Serv Med J. 1955;11(6):407-18.

2. Stephens KF. The likely role of the anaesthetist and of anaesthesia in the early surgical treatment of mass casualties. Proc R Soc Med. 1959;52(4):241-3.

3. Stephens KF, Bourne JG. Anaesthesia for mass casualties. Lancet. 1960;2(7148):481-2.

4. Adler L, Inkster JS. Anaesthesia for mass casualties. Another possible solution for disaster circumstances. Anaesthesia. 1967;22(1): 29-36.

5. Spain BT, Blum PG, Hams SC. The role of anaesthetists in the Darwin response to the Bali bombing. Anaesth Intensive Care. 2003;31(3):306-8. 
6. CRED, C.f.R.o.t.E.o.D.-. Natural disasters. 2020, School of Public Health and WHO: Brussels Belgium.

7. Rocque M, Duwe G. Rampage shootings: an historical, empirical, and theoretical overview. Curr Opin Psychol. 2018;19:28-33.

8. Magnus D, Khan MA, Proud WG. Epidemiology of civilian blast injuries inflicted by terrorist bombings from 1970-2016. Defence Technology. 2018;14(5):469-76 Epidemiological analysis of nearly five decades of blast injuries from terrorist civilian bombings. The article illustrates trends in frequency of terrorist attacks as well as global geographical locations of where most of the recent attacks have been occurring. Furthermore, the study also describes the casualties from the blast injuries associated from various settings.

9. Sternberg E, Lee GC, Huard D. Counting crises: US hospital evacuations, 1971-1999. Prehosp Disaster Med. 2004;19(2):150-7.

10. Dudaryk R, Pretto EA Jr. Resuscitation in a multiple casualty event. Anesthesiol Clin. 2013;31(1):85-106.

11.• Kuza CM, McIsaac JH III. Emergency preparedness and mass casualty considerations for anesthesiologists. Adv Anesth. 2018;36(1):39-66 Article outlining the epidemiology, classification, and management of mass casualties as it pertains to anesthesiologists. It provided an in-depth, systemic valuation of different disasters outlining the methodology one should approach each phase of a disaster. It provided a detailed explanation of variables for consideration including hospital management, operating room care, and post operative care.

12. Mannion SJ, Chaloner E. Principles of war surgery. BMJ. 2005;330(7506):1498-500.

13. Fares J, Fares MY, Fares Y. Medical schools in times of war: integrating conflict medicine in medical education. Surg Neurol Int. 2020;11:5.

14. Koenig K. In: Elia J, editor. COVID-19 as a medical disaster, in NEJM Clinical Conversations. Boston: Massachusettes Medical Society; 2020.

15. Today, M. Anesthesiologists 'ready to jump in' to help with COVID-19, in Infectiouos Disease COVID-19. M. Walker, Editor. 2020.

16. Zhang HF, Bo L, Lin Y, Li FX, Sun S, Lin HB, et al. Response of Chinese anesthesiologists to the COVID-19 outbreak. Anesthesiology. 2020;132:1333-8.

17. WHO. Glossary of humanitarian terms. [cited 20205 February 2020]; Available from: https:/www.who.int/hac/about/definitions/ en/

18. FEMA. Be prepared: have a family emergency plan. 2014 [cited 2020 Febraury 5, 2020]; Available from: https://www.fema.gov/ news-release/2014/06/11/be-prepared-have-family-emergencyplan.

19. King RV, Larkin GL, Klein KR, Fowler RL, Downs DL, North CS. Ranking the attributes of effective disaster responders and leaders. Disaster Med Public Health Prep. 2019;13(4):700-3.

20. The L. Trauma: a neglected US public health emergency. Lancet. 2016;388(10056):2058.

21. Perry INR, Stewart A. Use of medical countermeasures in smallscale emergency responses. Am J Public Health. 2018;108(53): S196-201.

22. Schumacher J, Arlidge J, Garnham F, Ahmad I. A randomised crossover simulation study comparing the impact of chemical, biological, radiological or nuclear substance personal protection equipment on the performance of advanced life support interventions. Anaesthesia. 2017;72(5):592-7.

23. Liang T. Handbook of COVID-19 prevention and treatment. Hangzhou: Jack Ma Foundation and Alibaba Foundation; 2020. p. 60.

24. Pretto EA Jr, Safar P. National medical response to mass disasters in the United States. Are we prepared? JAMA. 1991;266(9):1259 62 .
25. Soper RL. Anaesthesia for major disasters. Proc R Soc Med. 1959;52(4):239-41.

26. Dressler DP, Hozid JL, Giddon DB. The physician and mass casualty care: a survey of Massachusetts physicians. J Trauma. 1971;11(3):260-2.

27. Candiotti KA, et al. Emergency preparedness for biological and chemical incidents: a survey of anesthesiology residency programs in the United States. Anesth Analg. 2005;101(4):1135-40 table of contents.

28. Murshed H, Sultana R. Mass casualty management (Rana plaza tragedy) in secondary military hospital-anesthesiologist experience: case study. Disaster Mil Med. 2015;1:2.

29. Venticinque SG, Grathwohl KW. Critical care in the austere environment: providing exceptional care in unusual places. Crit Care Med. 2008;36(7 Suppl):S284-92.

30. Mukhtar A, Hasanin A, el-Adawy A, Osman S, Ahmed A, Nassar $\mathrm{H}$, et al. The Friday of rage of the Egyptian revolution: a unique role for anesthesiologists. Anesth Analg. 2012;114(4):862-5.

31. Ford P, Foale M. Converting gas-driven ventilators from oxygen to air. Anaesthesia. 2020;75:821.

32. Cone DC, Cummings BA. Hospital disaster staffing: if you call, will they come? Am J Disaster Med. 2006;1(1):28-36.

33. Solla, F., et al., Severe casualties from Bastille Day Attack in Nice, France. Eur J Trauma Emerg Surg, 2018.

34. King RV, Larkin GL, Fowler RL, Downs DL, North CS Characteristics of effective disaster responders and leaders: a survey of disaster medical practitioners. Disaster Med Public Health Prep. 2016;10(5):720-3.

35. King RV, et al. Ranking the attributes of effective disaster responders and leaders. Disaster Med Public Health Prep. 2019:14 Text outlining the top $\mathbf{1 0}$ attributes necessary for effective disaster relief management as leaders and responders. Results derived from a survey of 220 emergency and disaster medical response personel provide a systematic, experience-driven list of criteria to help with educational process when training and selecting personnel for disaster management.

36. Avidan V, Hersch M, Spira RM, Einav S, Goldberg S, Schecter W. Civilian hospital response to a mass casualty event: the role of the intensive care unit. J Trauma. 2007;62(5):1234-9.

37. Mangunta VR, Patel D. The era of mass casualty events: perspectives on care paradigms from a critical care anesthesiologist. Mo Med. 2019;116(1):49-52.

38. Baker DJ, Telion C, Carli P. Multiple casualty incidents: the prehospital role of the anesthesiologist in Europe. Anesthesiol Clin. 2007;25(1):179-88 xi.

39. Moszynski P. Extreme weather affects half a billion people each year. BMJ. 2007;335(7615):321.

40. Lowes, R. Hurricane Irma poses huge test for Florida hospitals. Medscape Medical News 2017 September 8, 2017; Available from: https://www.medscape.com/viewarticle/885469\#vp 2.

41. Earthquake Hazards Program. 2010 Available from: https:// earthquake.usgs.gov/earthquakes/eventpage/usp000h60h/impact.

42. McCunn M, Ashburn MA, Floyd TF, Schwab CW, Harrington P, Hanson CW III, et al. An organized, comprehensive, and securityenabled strategic response to the Haiti earthquake: a description of pre-deployment readiness preparation and preliminary experience from an academic anesthesiology department with no preexisting international disaster response program. Anesth Analg. 2010;111(6):1438-44.

43. Murray MJ. Ebola virus disease: a review of its past and present. Anesth Analg. 2015;121(3):798-809.

44. Chen, X., et al. Perioperative management of patients infected with the novel coronavirus: recommendation from the Joint Task Force of the Chinese Society of Anesthesiology and the Chinese Association of Anesthesiologists. Anesthesiology, 2020. One of the first society recommended guidelines for perioperative 
management of COVID positive patients based on WHO and National Health Commissions guidelines for prevention and treatment of this virus. Provided clinically relevant, experience derived recommendations to give early guidance how to provide care to those infected while mitigating risks to healthcare providers involved.

45. Li W, Huang J, Guo X, Zhao J, Mandell MS. Anesthesia management and perioperative infection control in patients with the novel coronavirus. J Cardiothorac Vasc Anesth. 2020.

46. Matava CT, Kovatsis PG, Summers JL, Castro P, Denning S, Yu J, et al. Pediatric airway management in COVID-19 patientsconsensus guidelines from the Society for Pediatric Anesthesia's pediatric difficult intubation collaborative and the Canadian pediatric anesthesia society. Anesth Analg. 2020; Publish Ahead of Print.

47. Thomas-Ruddel, D., et al., Coronavirus disease 2019 (COVID-19): update for anesthesiologists and intensivists March 2020. Anaesthesist, 2020.

48. Wujtewicz M, Dylczyk-Sommer A, Aszkiełowicz A, Zdanowski S, Piwowarczyk S, Owczuk R. COVID-19-what should anaethesiologists and intensivists know about it? Anaesthesiol Intensive Ther. 2020;52(1):34-41.

49. Zhang L, Li J, Zhou M, Chen Z. Summary of 20 tracheal intubation by anesthesiologists for patients with severe COVID-19 pneumonia: retrospective case series. J Anesth. 2020.

50. Zuo, M.Z., et al., Expert recommendations for tracheal intubation in critically ill patients with novel coronavirus disease 2019. Chin Med Sci J, 2020

51. Hubmayr RD, Farmer JC. Should we "rescue" patients with 2009 influenza A (H1N1) and lung injury from conventional mechanical ventilation? Chest. 2010;137(4):745-7.

52. de Jong, R.H., Nerve gas terrorism: a grim challenge to anesthesiologists. Anesth Analg, 2003. 96(3): p. 819-25, table of contents.
53. Talmor D. Nonconventional terror-the anesthesiologist's role in a nerve agent event. Anesthesiol Clin. 2007;25(1):189-99 xi.

54. Dichtwald S, Weinbroum AA. Bioterrorism and the anaesthesiologist's perspective. Best Pract Res Clin Anaesthesiol. 2008;22(3):477-502.

55. Cosar A, Kenar L. An anesthesiological approach to nerve agent victims. Mil Med. 2006;171(1):7-11.

56. McGann C, Miaullis A, Page N. Radiologists: the unsuspecting subject matter experts. J Am Coll Radiol. 2015;12(7):745-53.

57. After September 11. N Engl J Med, 2001. 345(20): p. 1490.

58. Olson KB. Aum Shinrikyo: once and future threat? Emerg Infect Dis. 1999;5(4):513-6.

59. Maiello ML, Cole J, Vernetti E. Bridging the expertise gap: developing and utilizing a radiological advisory committee for New York City. Health Secur. 2018;16(3):204-12.

60. Holcomb JB, Jenkins D, Rhee P, Johannigman J, Mahoney P, Mehta S, et al. Damage control resuscitation: directly addressing the early coagulopathy of trauma. J Trauma. 2007;62(2):307-10.

61. Borgman MA, Spinella PC, Perkins JG, Grathwohl KW, Repine T, Beekley AC, et al. The ratio of blood products transfused affects mortality in patients receiving massive transfusions at a combat support hospital. J Trauma. 2007;63(4):805-13.

62. Collaborators C-t, et al. Effects of tranexamic acid on death, vascular occlusive events, and blood transfusion in trauma patients with significant haemorrhage (CRASH-2): a randomised, placebocontrolled trial. Lancet. 2010;376(9734):23-32.

Publisher's Note Springer Nature remains neutral with regard to jurisdictional claims in published maps and institutional affiliations. 